\title{
Comparative Study on Egyptian Nuclear Research
}

\section{Centers}

\author{
Mohamed Farahat \\ Department of Sitting and Environment, Egyptian Nuclear and Radiological Regulatory Authority, Nasr City, Cairo 11787, Egypt
}

\begin{abstract}
This paper aims to study the architectural design and planning of the Egyptian nuclear research centers. Three Egyptian nuclear research centers and the proposed nuclear research center have been studied. These centers are the Nuclear Research Center in Inshas, the Hot laboratories and Waste Management Center in Inshas, the National Center for Radiation Research and Technology in Nasr City and the proposed Nuclear Research Center in North Western Coast of Egypt. Also, the paper aims to study the functions of these centers, as well as the types of their existing facilities. The paper investigates the principles and standards used in design and planning of these nuclear research centers. A comparative study has been conducted to those four nuclear research centers to evaluate the centers according to the site characteristics and the basic safety factors. The results were compared to determine the best design and planning. The proposed Nuclear Research Center in North Western Coast of Egypt proved to be the best among all with regard to design and planning, taking into consideration the radiation safety requirements. The architects are recommended to design and plan the nuclear research centers, taking into consideration the radial planning concept because it is the best with regard to radiation safety requirements.
\end{abstract}

Key words: Egyptian nuclear research centers, comparative study, architectural study, descriptive and analytical studies.

\section{Introduction}

Nuclear sciences have been developed to a stage which has a direct impact on the needs of the human. Nowadays, nuclear uses appear in various fields such as industry, agriculture and medicine. The majority of these developments have occurred in specialized centers called nuclear research centers. These centers have affected and will continue to affect with important role in supporting nuclear energy programs in all countries of the world which began to reap the benefits of these developments. Therefore, the importance of the presence of such centers could be observed. These centers are very important to continue the development operations in the nuclear fields. Also, they are very important to contribute in the training of new generations of scientists who will be responsible for development in the future [1].

Corresponding author: Mohamed Farahat, Ph.D., research field: architecture.

\section{Nuclear Research Centers}

Most developments in nuclear sciences were carried out in special centers in which nuclear materials and radioisotopes are used in promoting medicine, industry and agriculture. The importance of these centers for the continuous development of nuclear sciences and technology is well recognized since new fields of applications of nuclear materials and radioisotopes will remain always necessary. The nuclear research centers can be defined as research centers in which nuclear research can be achieved. The nuclear research center is normally like any scientific research centers in its buildings. Additional facilities which deal with the nuclear research have to be provided [1].

A nuclear research center may provide facilities for several research fields and operations. The activities in these centers involve basic and applied research, product development, material testing, applications, process development involving the use of research reactors, industrial irradiators, accelerators, 
radioactive materials and radioisotopes. The activities and facilities included in a nuclear research center put constrains on the characteristics of the sites where it is located and on the design aspects which should assure the safety for people and environment. In these centers, protection against hazards of ionizing radiations is one of the basic duties of the administrations and the workers. Any nuclear research center has architectural program which consists of all or some of the facilities [1].

\section{Egyptian Nuclear Research Centers}

Early on, Egypt had the vision of embarking into the atomic age and foresaw the vital role of peaceful applications of atomic energy. In 1955, the Egyptian Atomic Energy Commission was established and in 1957, Act No. 288 promulgated establishing the Atomic Energy Establishment. Then, it was developed over the years to be the country's leading institution in promoting the peaceful applications of nuclear science and technology in different fields. This covers fields of health, food, agriculture, environment, water resources, oil and mineral resources and a good spectrum of the industry [2].

The Atomic Energy Authority consists of three major scientific centers, namely, the NRC (Nuclear Research Center) in Inshas, the HLWMC (Hot Laboratories and Waste Management Center) in Inshas and the NCRRT (National Center for Radiation Research and Technology) in Nasr City (Fig. 1).

These centers are subdivided into major research divisions. In the past two decades, the EAEA (Egyptian Atomic Energy Authority) has embarked into the implementation of big nuclear projects, aiming at maximizing the practical peaceful applications of nuclear technology. This included Egypt's Second Research Reactor, the cyclotron accelerator, advanced irradiation facilities, etc. (Fig. 2) [4].

\subsection{Nuclear Research Center in Inshas}

The NRC is the oldest and the biggest research

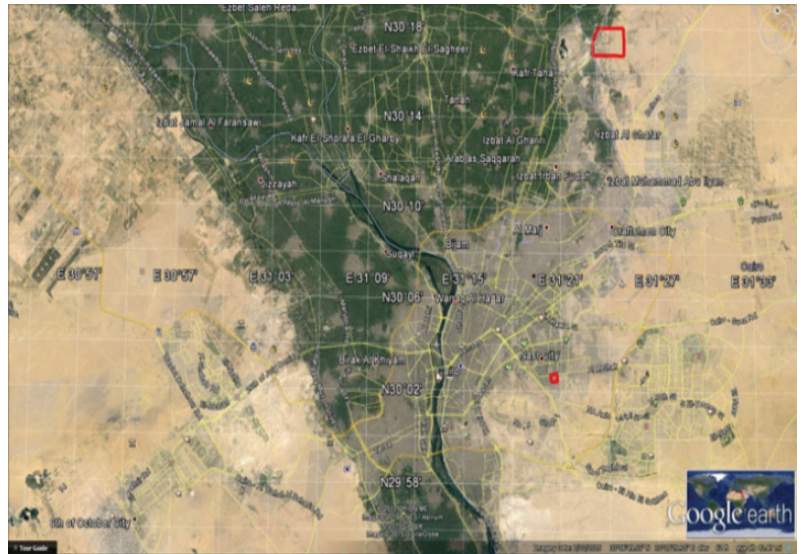

Fig. 1 Map of the Greater Cairo Governorates illustrates the locations of NRC in Inshas, HLWMC in Inshas and NCRRT in Nasr City [3].

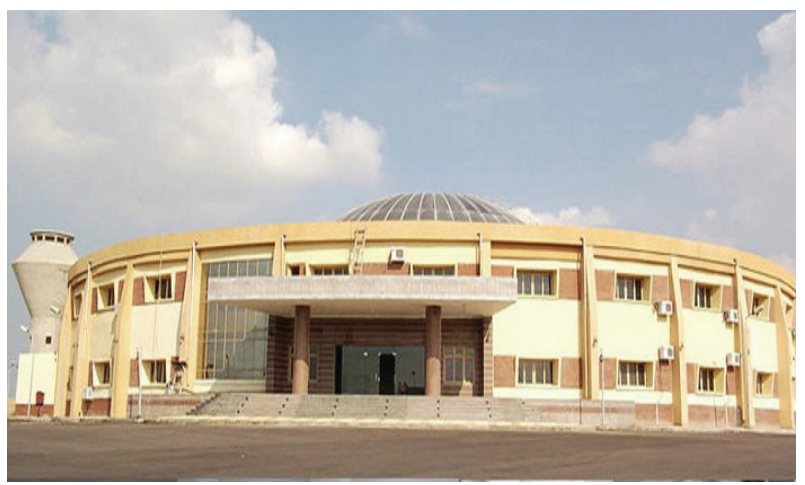

(a)

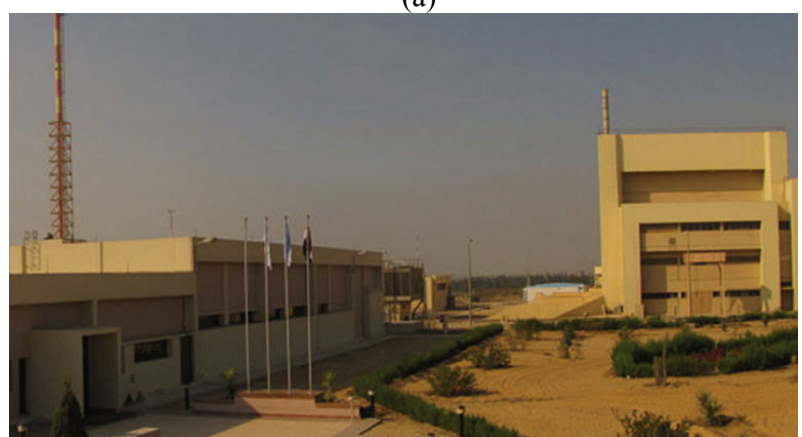

(b)

Fig. 2 Some buildings of Egyptian Atomic Energy Authority: (a) engineering building; (b) Second Research Reactor and radioisotopes production facility [2].

institute of the EAEA (Fig. 3). It is located in Inshas and its activities are directed towards the basic nuclear science, reactors, nuclear reactor materials, electronic instrumentation and applications of radioisotopes in medicine, industry, agriculture, etc. (Fig. 4) [2].

3.1.1 Egypt's Second Research Reactor ETRR-2

Egypt's Second Research Reactor is a multi-purpose 


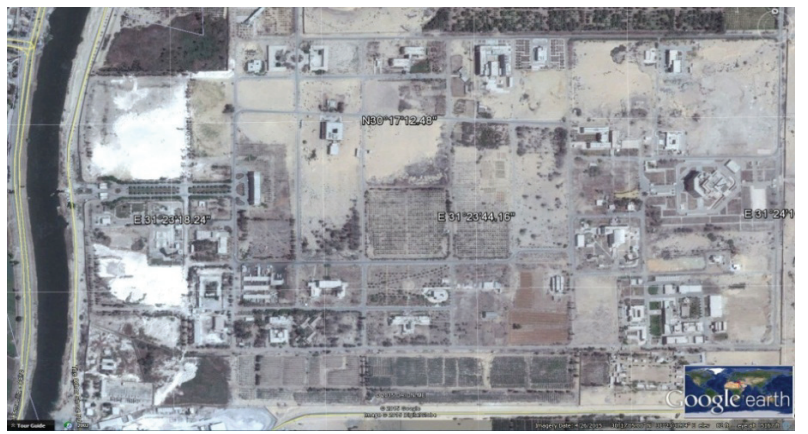

Fig. 3 Layout of NRC and HLWMC [3].

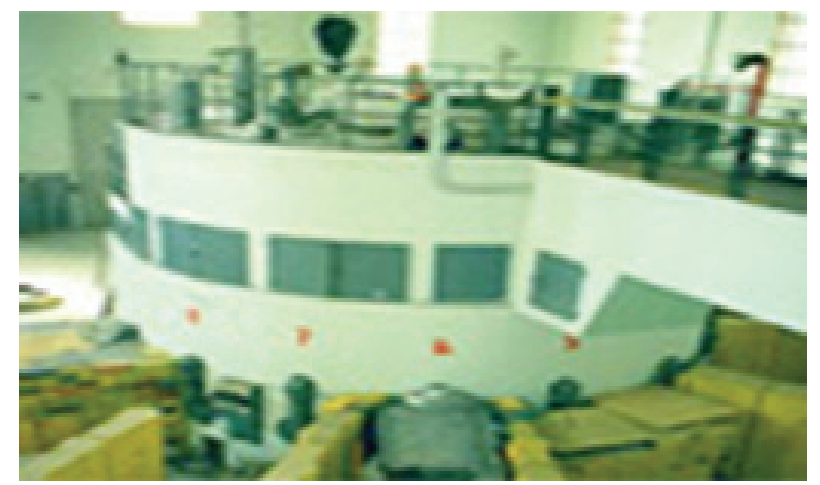

Fig. 4 Egypt's First Research Reactor ETRR-1 [2].

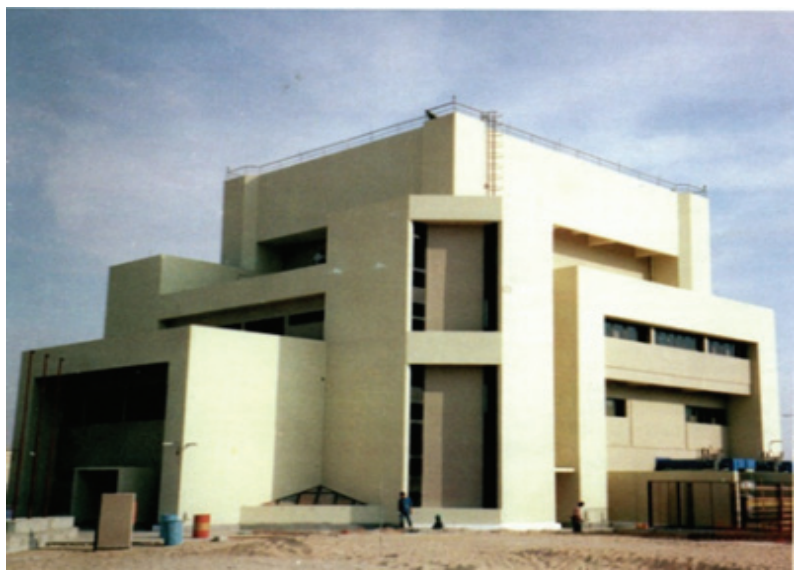

Fig. 5 Egypt's Second Research Reactor ETRR-2 [4].

reactor utilized for advanced research and development applications (Fig. 5). This is a $22 \mathrm{MW}$ thermal reactor, with a neutron flux [5]. Utilization of the reactor includes fundamental research, radioisotope production for medical, industrial, and other applications, neutron irradiation, neutron radiography and neutron activation analysis, etc. [6].

3.1.2 Nuclear Fuel Manufacturing Pilot Plant

The reactor fuel is manufactured in the fuel manufacturing plant (Fig. 6). This is a plate type fuel element $\left(19.75 \%\right.$ enriched $\left.\mathrm{U}_{3} \mathrm{O}_{8}\right)$, cladded with aluminum [5]. The reactor, the fuel manufacturing plant and the attached radioisotope production facility represent an important development in the utilization of nuclear technology in Egypt for peaceful purposes [7].

\subsubsection{The Cyclotron Accelerator}

This is a charged particle accelerator, $20 \mathrm{MeV}$, ion beam current. It accelerates protons, deuteron and helium. It is a Russian type, facility acquired through an IAEA TC program (Fig. 7). The accelerator is equipped with channels for short lived radioisotope production, for fast neutron production $(>4 \mathrm{MeV})$ and for materials science industrial application. The cyclotron accelerator has also provisions of sensitive nuclear techniques for microanalysis in fields related to environment, geology, physics, chemistry, biology, archaeology and materials (Fig. 8) [2].

3.1.4 Central Laboratory for Isotopes and Elemental Analysis

The Central Laboratory for Isotopes and Elemental

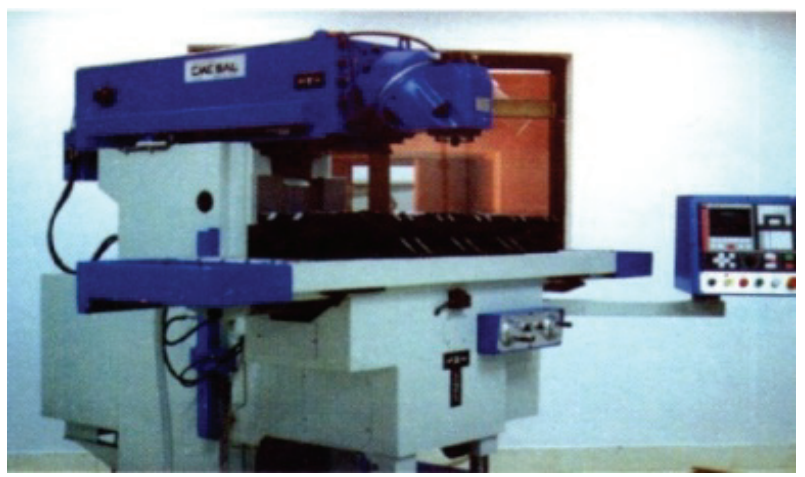

Fig. 6 Fuel plates machines [5].

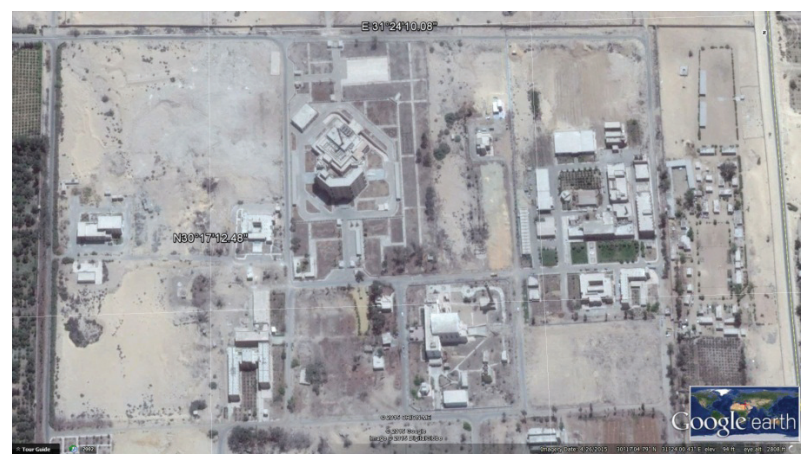

Fig. 7 Layout illustrates the cyclotron accelerator, Egypt First Research Reactor and HLWMC [3]. 


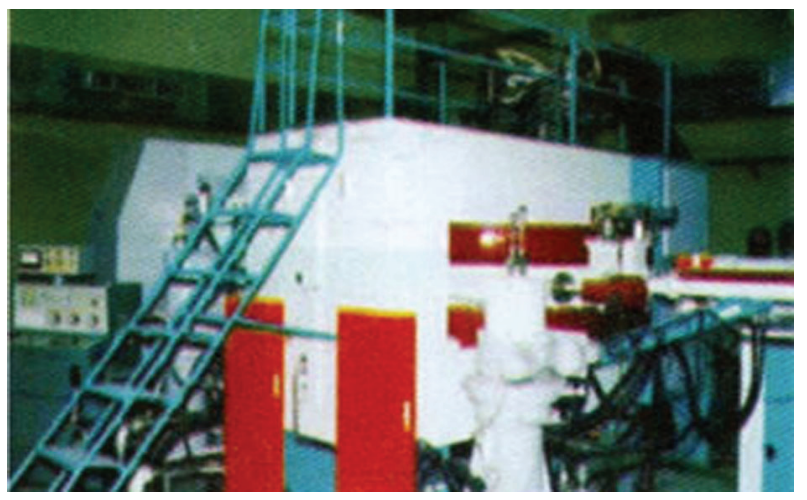

Fig. 8 Cyclotron accelerator [2].

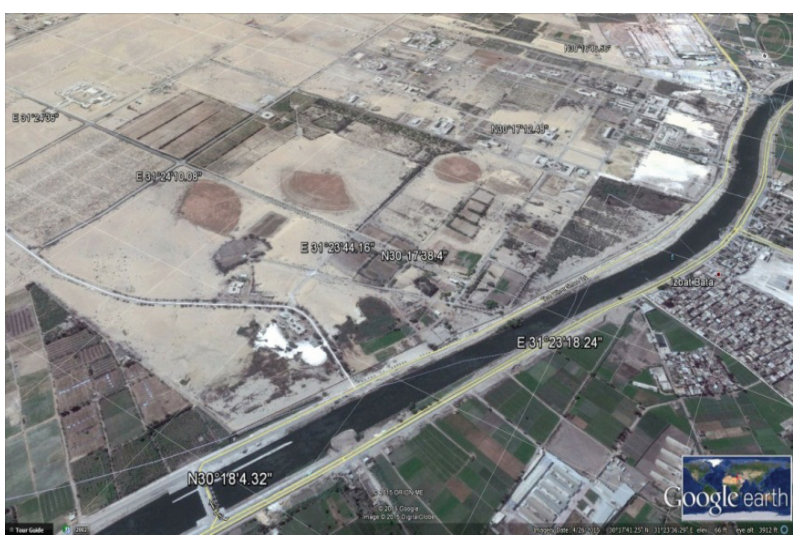

Fig. 9 Perspective from the east direction of NRC and HLWMC [3].

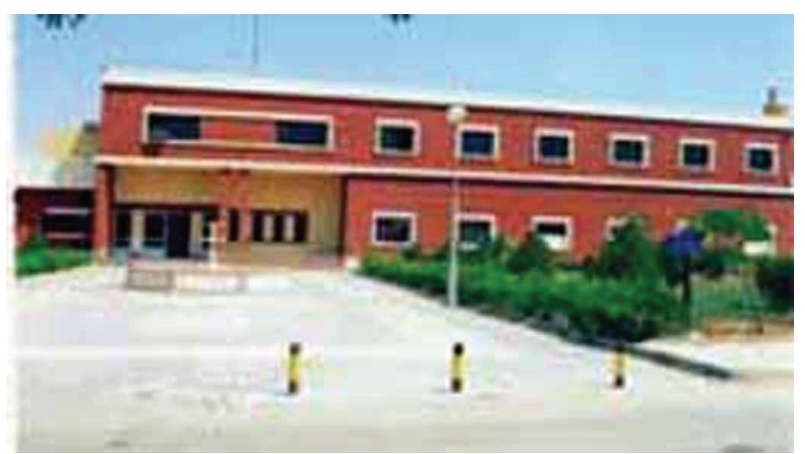

Fig. 10 HLWMC (Hot Laboratories and Waste Management Center) [2].

Analysis is provided with ion plasma-mass spectrometer. The high separation power helps avoiding the interfering problems that arise during analysis of elements or compounds having close masses. In addition, the instrument has a laser scanning facility to analyze the solid samples without any chemical treatment [2].

\subsubsection{Neutron Activation Analysis Laboratory}

Neutron activation analysis is used to detect the toxic dangerous environmental pollutants. These pollutants include heavy and light metals resulting from polluting industries (iron and steel, fertilizers and cement), lead emitted through cars exhaust as well as other toxic elements such as antimony, tin, cadmium and beryllium [2].

3.1.6 Central Laboratories for Isotopes Applications

These laboratories aim at investing the capabilities of the highly technical staff members and advanced equipment to offer services and training. These central laboratories include laboratories of molecular biology, micro technology, radiation counting and chemical analysis, molecular microbiology and tissues culture, and laboratory of Nitrogen-15 [2].

\subsection{Hot Laboratories and Waste Management Center in Inshas}

The HLWMC was established in 1980 (Fig. 9). Its purpose is development of expertise in the fields of radiation waste treatment, radioactive waste management, production of radioisotopes for various medical and industrial applications, as well as production of labeled pharmaceutical compounds that are widely used for medical diagnosis (Fig. 10) [2].

3.2.1 Unit of Production of Freeze-Dried Kits for Technetium Generator $\left({ }^{99 m} \mathrm{Tc}\right)$ Labeling

Tasks of this unit are not limited to the production of some radioactive labeled pharmaceutical compounds; They also involve performing quality control check on them to ensure that the products comply with the international standards [2]. The quality control tests include the following determination of chemical and radiochemical purity, sterility, the reducing agent contents and determination of moisture contents [7].

\subsubsection{Analytical Services Laboratory}

This laboratory was established in 1998 in order to offer accurate chemical analysis to all sectors of the society. It contains much analytical modern equipment such as atomic absorption spectrometer, inductively coupled plasma spectrometer, XRD 
(X-ray diffraction), XRF (X-ray fluorescence), total reflection X-ray fluorescence and thermal analysis instruments [2].

\subsubsection{Mobile Laboratory}

The mobile lab is a car (van) equipped with the necessary radiation detectors. It is very useful in emergency cases. It can move to the area of interest to carry out the required measurements and facilitate the actions to be taken [4].

\subsection{National Center for Radiation Research and Technology in Nasr City}

NCRRT was established in 1972 aiming to promote research and development using ionizing radiation in different fields of ionizing radiation in medical, industrial, agricultural, environmental and other applications (Fig. 11) [4].

The NCRRT contains three major gamma irradiator facilities, namely Egypt's mega gamma-1 irradiator, Alexandria gamma irradiator and electron beam accelerator. These facilities are used for sterilization of health care products, preservation of agricultural products, industrial applications and scientific research. It also contains four research gamma irradiators (Fig. 12) [4].

Over the last decade, as a first trial of its sort in the Middle Eastern and African region, Egypt has embarked on a program of technology transfer of industrial radiation processing in view of its contribution to national development programs. A central body, the NCRRT (National Center for Radiation Research and Technology) has been established since 1973 to draw a national policy for radiation research and technology application to meet the local needs. Besides, the NCRRT objectives consider extending its scientific, technical and training services within the frame work of its infrastructure, to other neighboring countries on the regional level (Fig. 13) [2].

NCRRT has emerged as a complex spread over an area of $87,000 \mathrm{~m}^{2}$ (Fig. 14), housing four major buildings for industrial gamma radiation processing and electron beam processing, a $3 \mathrm{MW}$ power station and various workshops and ancillary services. The laboratories are distributed between the former two buildings [2]. The residential buildings surround the NCRRT (Fig. 15).

\subsubsection{The Administration Building}

The building consists of basement floor, ground floor, mezzanine floor, seven typical floors. The building

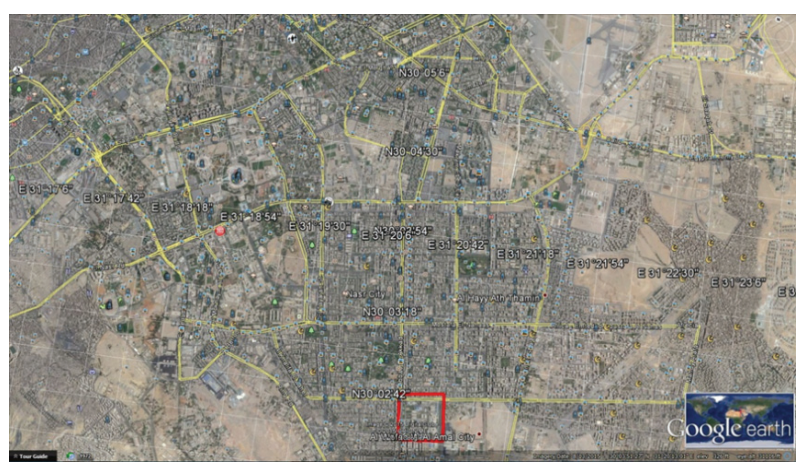

Fig. 11 Map of Nasr City illustrates the location of NCRRT [3].

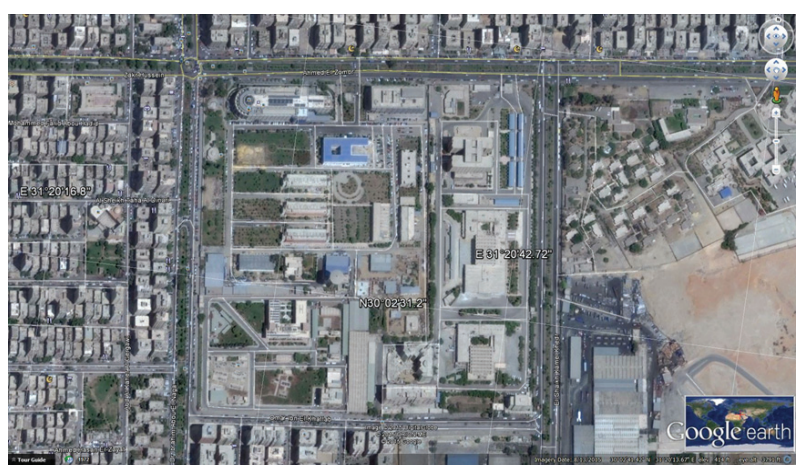

Fig. 12 Layout of NCRRT, ENPPI Petroleum Company, Petroleum Research Institute, Petroleum Sector Information Center and New and Renewable Energy Authority in Nasr city [3].

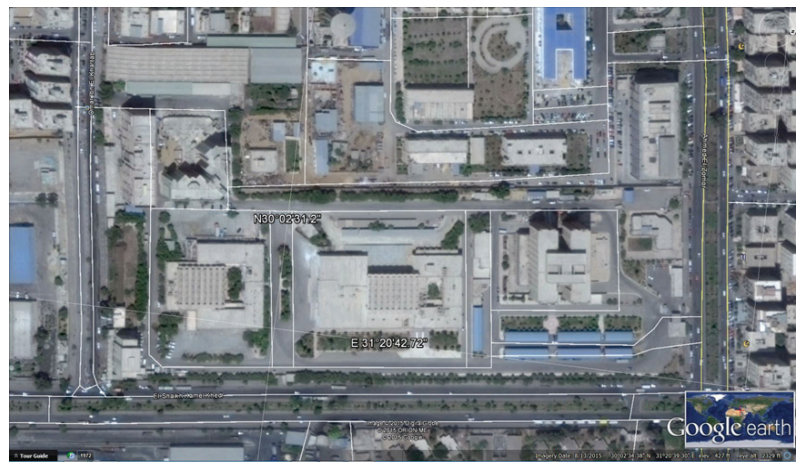

Fig. 13 Layout of NCRRT in Nasr City [3]. 


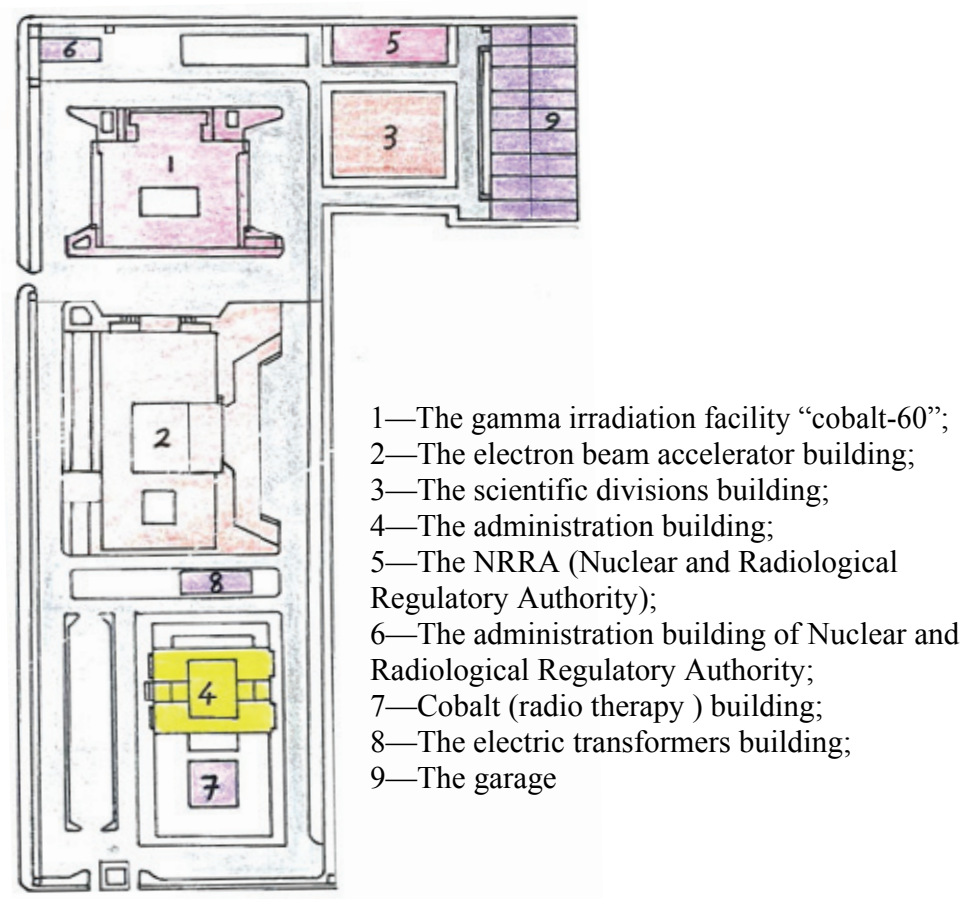

Fig. 14 Layout of NCRRT and NRRA in Nasr City [8].

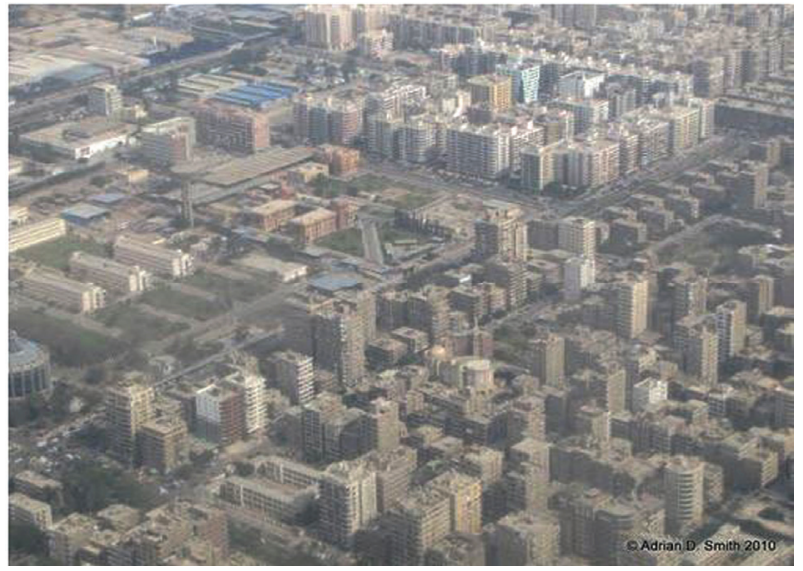

Fig. 15 Perspective shows the residential buildings which surround the NCRRT [3].

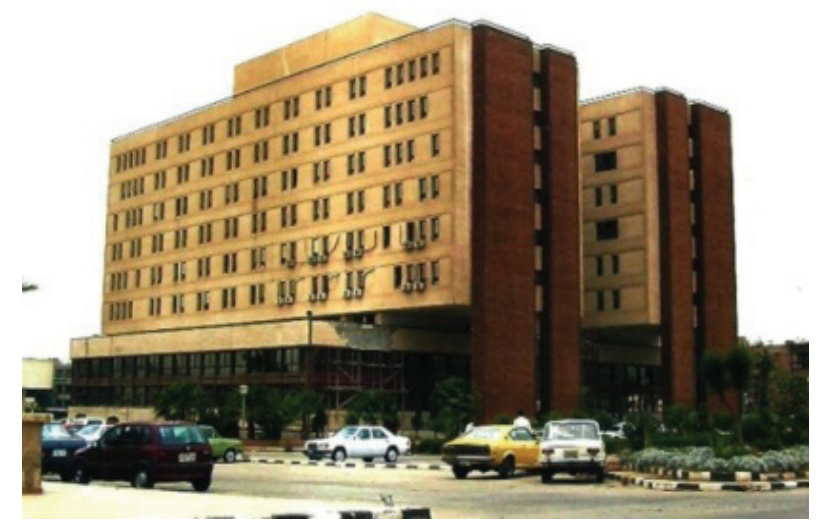

Fig. 16 General view of the administration building [4]. contains administration offices, employees' offices, personnel affairs, libraries, a design center, medical clinics, a training center, the office of the authority chairman, the offices of the authority vice-chairman, advisors offices, reception halls, meeting halls, a conference center, lecture halls, guests' rooms, a cafeteria, a prayer hall, security rooms, control rooms, stores, courts, toilets, water tanks, staircases, elevators, pumps rooms, electricity rooms and a garage (Fig. 16) [4].

\subsubsection{The Electron Beam Accelerator}

This is a 1.5 million electron volt accelerator which was established in the National Centre for Research and Technology in order to promote radiation processing by electron beam technology on an industrial scale for medical and industrial applications (Fig. 17). The work plan of the accelerator aims at developing heat shrinkable materials, hydrogels for medical use and surface treatment [4].

\subsubsection{The Gamma Irradiation Facility "Cobalt-60"}

The mega gamma irradiation facility (500.000 Curie) is the only unit in Egypt capable of sterilizing medical and agricultural products as well as industrial irradiation 


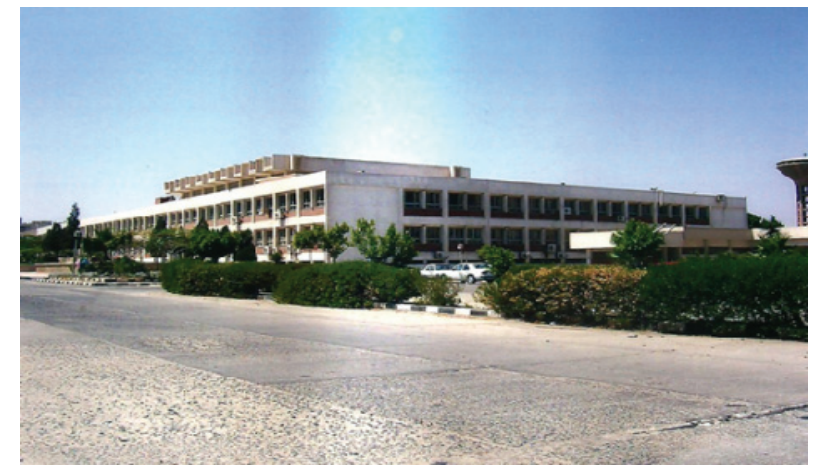

Fig. 17 General view of the Electron Beam Accelerator Building [4].

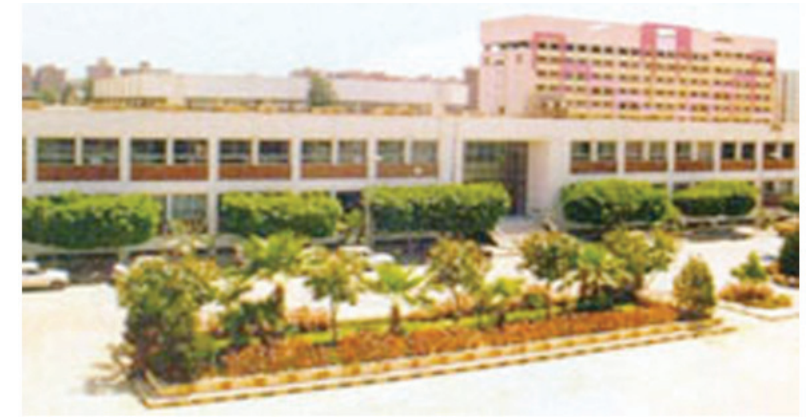

Fig. 18 Cobalt 60 Industrial Unit [2].

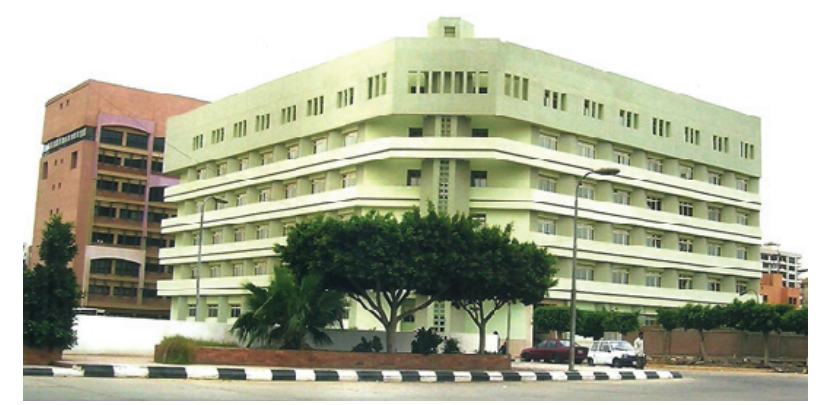

Fig. 19 General view of the scientific divisions building [4].

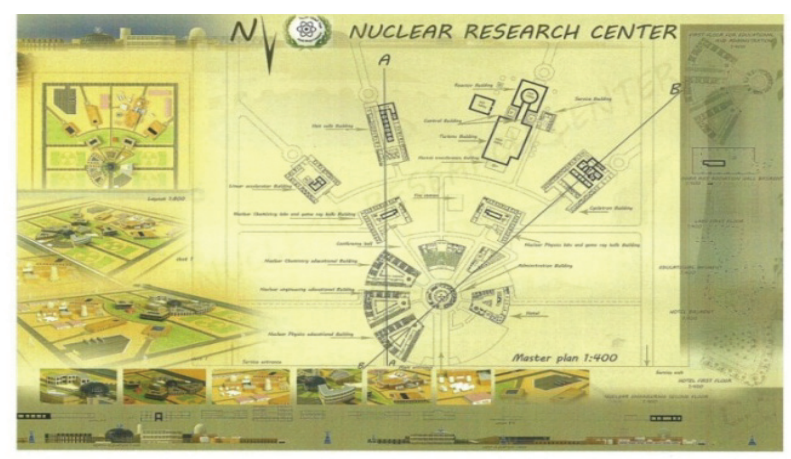

Fig. 20 Architectural design of the proposed nuclear research center.

research and applications (Fig. 18).

The activity of mega gamma co-60 facility will be increased (700.000 Curie) in order to meet the market demand for irradiated food and healthcare products. However, such upgrading seems to be not sufficient for the wide demand of medical companies especially those who are going to increase their export capacity of irradiated medical products [2].

\subsubsection{Scientific Divisions Building}

The building consists of basement floor, ground floor, five typical floors. The building contains the offices of the three scientific divisions, nuclear chemistry laboratories, nuclear physics laboratories, nuclear engineering laboratories, nuclear biology laboratories, nuclear agriculture laboratories, staff offices, libraries, the offices of the three scientific divisions chairmen, reception halls, meeting halls, conference halls, lecture halls, a cafeteria, a prayer hall, security rooms, control rooms, stores, courts, toilets, water tanks, staircases, elevators, pumps rooms, electricity rooms and a garage (Fig. 19) [4].

\subsubsection{Central Laboratories}

These laboratories provide advanced analytical services for different research sectors in the center and outside it. The analyzed samples could be natural (animal, plant, rocky samples, etc.) or synthesized ones. The analysis could be performed for samples in the solid or liquid form [2].

\subsubsection{Semi-Pilot Units}

These units were established in the early sixties of the 20th century in order to apply irradiation processing technology in some industries, e.g., cement, rubber and glass industries to produce some products with improved properties [2].

\subsection{Proposed Nuclear Research Center in North Western Coast of Egypt}

The proposed nuclear research center could be located in a semi-rural area in north western coast of Egypt (Fig. 20). The center will function as a new focal point for conducting nuclear research activities for the northern part of Egypt because the only nuclear research centers are existing in Inshas $(40 \mathrm{~km}$ from Cairo) and Nasr city. The topography of the area is 
typical of the north western coast. The coastal zone of the western desert has a rather special climate which differs from the climate of the inland desert area to the south. It is characterized by a high humidity and small diurnal temperature variations [9]. The prevailing wind direction is north to north west. The prevailing northerly winds require that hot zones should be located in the southern portion of the site. On the other hand, cold zone should be located in the northern portion of the site. The site of the nuclear research center can be served by the main regional highway. The coastal road from Alexandria to Marsa Matruh and Sallum connects the site with the national highway network [9].

It is assumed that the proposed center would include some basic facilities and machines that are necessary for developing the necessary research activities and different applications in the nuclear field (Fig. 21). This is necessary for manpower development in the northern region of Egypt as well as for the necessary socio-economic development of that region. It is expected to place the facilities in the site (Table 1). All these facilities were taken into consideration while developing a master plan of the center.

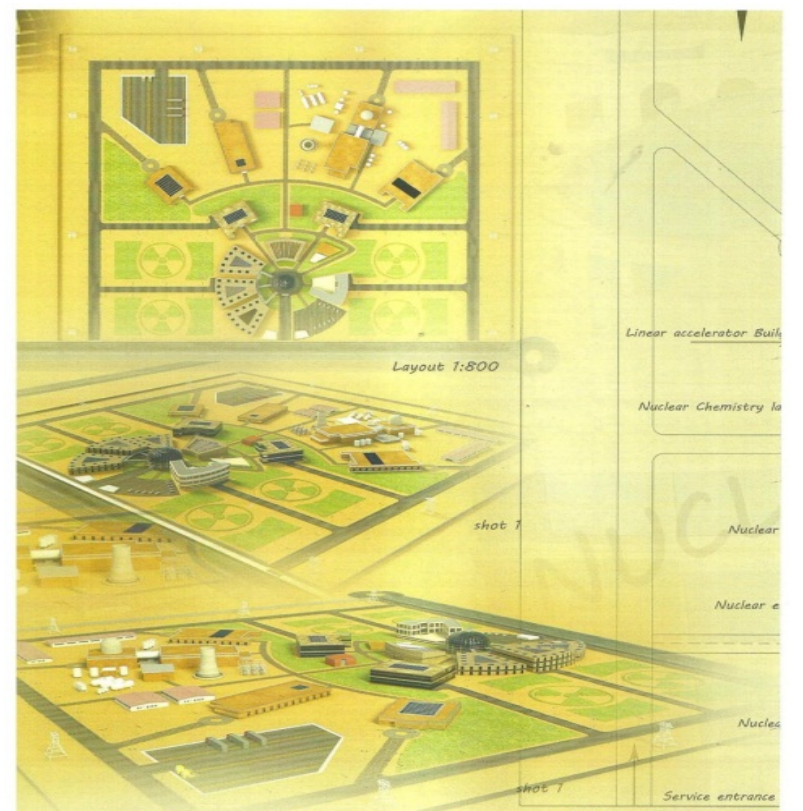

Fig. 21 Layout and shots of the proposed nuclear research center.

Table 1 Buildings of Egyptian nuclear research centers.

\begin{tabular}{|c|c|c|c|c|c|}
\hline No. & Building name & $\begin{array}{l}\text { Center } 1 \\
\text { (grid concept) }\end{array}$ & $\begin{array}{l}\text { Center } 2 \\
\text { (grid concept) }\end{array}$ & $\begin{array}{l}\text { Center } 3 \\
\text { (linear concept) }\end{array}$ & $\begin{array}{l}\text { Center } 4 \\
\text { (radial concept) }\end{array}$ \\
\hline 1 & Nuclear chemistry laboratories & $\sqrt{ }$ & $\sqrt{ }$ & $\sqrt{ }$ & $\sqrt{ }$ \\
\hline 2 & Nuclear engineering laboratories & $\sqrt{ }$ & $\sqrt{ }$ & $\sqrt{ }$ & $\sqrt{ }$ \\
\hline 3 & Nuclear physics laboratories & $\sqrt{ }$ & $\sqrt{ }$ & $\sqrt{ }$ & $\sqrt{ }$ \\
\hline 4 & Monitoring building & $\sqrt{ }$ & $\sqrt{ }$ & $\sqrt{ }$ & $\sqrt{ }$ \\
\hline 5 & Administration building & $\sqrt{ }$ & $\sqrt{ }$ & $\sqrt{ }$ & $\sqrt{ }$ \\
\hline 6 & Conference halls & $\sqrt{ }$ & $\sqrt{ }$ & $\sqrt{ }$ & $\sqrt{ }$ \\
\hline 7 & Library & $\sqrt{ }$ & $\sqrt{ }$ & $\sqrt{ }$ & $\sqrt{ }$ \\
\hline 8 & Cafeteria (canteen) & - & - & - & $\sqrt{ }$ \\
\hline 9 & Boiler building & - & - & - & $\sqrt{ }$ \\
\hline 10 & Workshops & $\sqrt{ }$ & $\sqrt{ }$ & $\sqrt{ }$ & $\sqrt{ }$ \\
\hline 11 & Fire station & $\sqrt{ }$ & $\sqrt{ }$ & $\sqrt{ }$ & $\sqrt{ }$ \\
\hline 12 & Guest house & $\sqrt{ }$ & $\sqrt{ }$ & - & $\sqrt{ }$ \\
\hline 13 & Low-activity level laboratories & $\sqrt{ }$ & $\sqrt{ }$ & $\sqrt{ }$ & $\sqrt{ }$ \\
\hline 14 & Gamma rays units & - & - & $\sqrt{ }$ & $\sqrt{ }$ \\
\hline 15 & Research reactors $(<30 \mathrm{MW})$ & $\sqrt{ }$ & - & - & $\sqrt{ }$ \\
\hline 16 & Cyclotrons & $\sqrt{ }$ & - & - & $\sqrt{ }$ \\
\hline 17 & Accelerators & $\sqrt{ }$ & - & $\sqrt{ }$ & $\sqrt{ }$ \\
\hline 18 & Hot laboratories (hot cells) & - & $\sqrt{ }$ & - & $\sqrt{ }$ \\
\hline 19 & Radioisotopes production facilities & $\sqrt{ }$ & $\sqrt{ }$ & - & $\sqrt{ }$ \\
\hline \multirow[t]{2}{*}{20} & $\begin{array}{l}\text { Decontamination facilities (waste treatment } \\
\text { facility and water treatment facility) }\end{array}$ & - & $\sqrt{ }$ & - & $\sqrt{ }$ \\
\hline & Rate & 15 & 14 & 12 & 20 \\
\hline
\end{tabular}




\section{Site Characteristics of Nuclear Research Centers}

Site selection for placing a nuclear research center is a very important step. Since the site characteristics have their impact on the centers designs, many factors should be taken into consideration in the siting of nuclear research centers. These factors include location, population distribution, external human-induced events, historical significance, hydrology, geology, meteorology, etc. [10]. These site characteristics could influence center design and operation criteria. The adequacy of the site characteristics should be considered and investigated from the safety point of view.

\section{Principals and Standards Used in Planning and Designing of Nuclear Research Centers}

The architectural principles and standards of nuclear research centers are different from other research centers. The nature of the radioactive materials to be handled and the type of work to be carried out in the center will determine the planning and designing of the center.

\subsection{General Planning and Designing of Nuclear Research Centers}

The main problem when considering the master plan for a nuclear research center is to provide effectively for future expansion. Most research centers have grown enormously. Therefore, the principle object in planning is to provide for future expansion to take place without hindering the development of research. For that, a nuclear research center site should not be located in or near a heavily built-area. Ideally, a nuclear research center is best situated in rural or semi-rural districts in which a certain degree of isolation may be achieved. In addition, in these districts, extra free space around the center should be available for future expansions [11].
The design concepts of town planning include grid concept, linear concept, radial concept, centralized concept and clustered concept. In drawing up a master plan, the methods used in town planning must be used. These methods can be summarized as follows:

(1) Centralized: It consists of a central dominant space about which a number of secondary spaces are grouped;

(2) Linear: It consists of linear sequences of repetitive spaces;

(3) Radial: It consists of a central space from which linear organizations of space extend in a radial manner;

(4) Clustered: It consists of spaces grouped by sharing of a common visual relationship;

(5) Grid: It consists of spaces organized within the field of a structural or other three-dimensional grid.

Different aspects should be considered in the master plan of nuclear research centers. Traffic routes have to be established. The site should be zoned for development. Areas must be set aside for each of the departments of the center, large enough to provide for growth, and so grouped that development will not interfere with the basic inner circulation routes in the site. The central focus composed of buildings such as the library, administration and the cafeteria, which may serve all other departments [11].

\subsection{Features of Nuclear Research Center Master Plan}

The buildings in a nuclear research center should be segregated according to the levels of radioactivity in each one of them. The radioactive buildings designed on the system of segregation should be planned from cold to hot areas. The center should contain cold zone, warm zone and hot zone [11].

\section{Analytical Architectural Study of Egyptian Nuclear Research Centers}

The centers under study are:

(1) NRC in Inshas: grid concept;

(2) HLWMC in Inshas: grid concept; 
(3) NCRRT in Nasr City: linear concept;

(4) proposed NRC in North Western Coast of Egypt: radial concept.

Nuclear Research Center and Hot Laboratories and Waste Management Center in Inshas have been designed according to grid concept, while National Center for Radiation Research and Technology in Nasr City has been designed according to linear concept. Proposed Nuclear Research Center in North Western Coast of Egypt has been designed according to radial concept. Table 1 shows the buildings of Egyptian nuclear research centers.

These nuclear research centers have been studied and evaluated in relation to site characteristics (essential safety and technical factors). These factors include: location, topography and levels, climatic factors, soil conditions, economic conditions, main function of the nuclear research center, radiation safety and radiation protection, security, function relation between the buildings, design concept (idea of design), natural environmental systems and preservation of the environment, administration facilities, waste treatment facility, infrastructures for expansion, human activities and existing development, flexibility and ease of movement in accordance with the requirements of IAEA, population distribution, positive impact effects, negative impact effects, aesthetics, transportation to and from the site (harbors, railways, highways, etc.), reactor space site, services routes, visual concept, positive aspects of the design, negative aspects of the design and dominant character and thought.

It is noticed that these factors are very important factors which could proposed for evaluation. The results of this evaluation are summarized in Table 2 .

It could be observed in Table 2 that the proposed Nuclear Research Center in North Western Coast of Egypt (the radial concept) (Figs. 20 and 21) is the optimum one because it has big advantages over the others especially in terms of location, radiation safety, function relation between the buildings, services routes, aesthetics and waste treatment facility.

It could be observed in this center (radial concept) that:

The center was designed based on the system of segregation according to which the different buildings were distributed in the site according to the level of radioactivity in these buildings as shown in Figs. 20 and 21. The different zones of the site are:

(1) The cold zone is located in the northern portion of the site and includes nuclear chemistry laboratories, nuclear engineering laboratories, nuclear physics laboratories, monitoring building, administration building, conference hall, library, workshops, fire station, cafeteria (canteen) and guest house;

(2) The warm zone is located in the middle of the site and includes buildings for experimentation at low or warm level of radioactivity. It includes low-activity level laboratories, gamma rays units, nuclear physics laboratories and nuclear chemistry laboratories;

(3) The hot zone is located in the southern portion of the site and includes research reactor (30 MW), cyclotron, hot laboratories (hot cells), linear accelerator, boiler and power station, radioisotopes production facilities, decontamination facilities (waste treatment facility and water treatment facility).

Because of the northerly prevailing winds, hot zone is located in the southern portion of the site and cold zone is located in the northern portion of the site. The main checking-in point (for workers and materials) is located in the administration building, which is closed to the entrance. A network of wide roads is provided inside the center to facilitate the ingress of materials and equipment. Fences are provided around the site for physical protection. Around the planned buildings, there is an area which is kept for future expansion of the center. 
Table 2 Evaluation of site characteristics and essential safety and technical factors for Egyptian nuclear research centers which have different design concept.

\begin{tabular}{|c|c|c|c|c|c|c|}
\hline No. & $\begin{array}{l}\text { Site characteristics (essential safety and technical } \\
\text { factors) }\end{array}$ & $\begin{array}{l}\text { Proposed } \\
\text { rate }(\%) \\
\text { grade } \\
\end{array}$ & $\begin{array}{l}\text { Center } 1 \\
\text { (grid c.) } \\
\text { grade } \\
\end{array}$ & $\begin{array}{l}\text { Center } 2 \\
\text { (grid c.) } \\
\text { grade } \\
\end{array}$ & $\begin{array}{l}\text { Center } 3 \\
\text { (linear c.) } \\
\text { grade }\end{array}$ & $\begin{array}{l}\text { Center } 4 \\
\text { (radial c.) } \\
\text { grade }\end{array}$ \\
\hline 1 & Location & 4 & 3 & 3 & 2.5 & 3.5 \\
\hline 2 & Topography and levels & 4 & 3 & 3 & 2.5 & 3 \\
\hline 3 & Climatic factors & 4 & 2.5 & 2.5 & 2 & 3.5 \\
\hline 4 & Soil conditions & 4 & 2.5 & 2.5 & 2.5 & 3 \\
\hline 5 & Economic conditions & 4 & 3 & 3 & 2.5 & 3.5 \\
\hline 6 & Main function of the nuclear research center & 4 & 3.5 & 3.5 & 3 & 3.5 \\
\hline 7 & Radiation safety and radiation protection & 4 & 3 & 3 & 2.5 & 3.5 \\
\hline 8 & Security & 4 & 3.5 & 3.5 & 3 & 3.5 \\
\hline 9 & Function relation between the buildings & 4 & 3 & 3 & 2.5 & 3.5 \\
\hline 10 & Design concept (idea of design) & 4 & 3 & 3 & 2.5 & 3.5 \\
\hline 11 & $\begin{array}{l}\text { Natural environmental systems and preservation } \\
\text { of the environment }\end{array}$ & 4 & 3 & 3 & 2.5 & 3 \\
\hline 12 & Administration facilities & 4 & 2.5 & 2.5 & 2.5 & 3.5 \\
\hline 13 & Waste treatment facility & 4 & 3 & 3 & 3 & 3.5 \\
\hline 14 & Infrastructures for expansion & 4 & 3.5 & 3.5 & 2 & 3.5 \\
\hline 15 & Human activities and existing development & 4 & 2.5 & 2 & 2 & 3 \\
\hline 16 & $\begin{array}{l}\text { Flexibility and ease of movement in accordance } \\
\text { with the requirements of International Atomic } \\
\text { Energy Agency }\end{array}$ & 4 & 3 & 3 & 2 & 3 \\
\hline 17 & Population distribution & 4 & 3 & 3 & 2 & 3.5 \\
\hline 18 & Positive impact effects & 4 & 3.5 & 3 & 2 & 3 \\
\hline 19 & Negative impact effects & 4 & 3 & 3 & 2 & 3.5 \\
\hline 20 & Aesthetics & 3 & 2.5 & 2 & 2 & 3 \\
\hline 21 & $\begin{array}{l}\text { Transportation to and from the site (harbors, } \\
\text { railways, highways, etc.) }\end{array}$ & 3 & 2 & 2 & 2 & 3 \\
\hline 22 & Reactor space site & 3 & 2.5 & 2.5 & 1.5 & 3 \\
\hline 23 & Services routes & 3 & 2.5 & 2.5 & 2 & 3 \\
\hline 24 & Visual concept & 3 & 2 & 2 & 2 & 2.5 \\
\hline 25 & Positive aspects of the design & 3 & 2 & 2 & 1.5 & 2 \\
\hline 26 & Negative aspects of the design & 3 & 2.5 & 2 & 2 & 2.5 \\
\hline \multirow[t]{2}{*}{27} & Dominant character and thought & 3 & 2 & 2 & 1.5 & 2.5 \\
\hline & Total & 100 & 75 & 73 & 60 & 85 \\
\hline
\end{tabular}

\section{Results and Conclusions}

Nuclear sciences and technologies have been developed to a stage which has a direct impact on the human needs for development. Site selection for placing a nuclear research center is a very important aspect. Many factors should be taken into consideration such as location, geology, etc. The nuclear research centers sites should not be located in or near a heavily built-area and is best situated in a rural or semi-rural districts.

The master plan of a nuclear research center should be designed based on the system of segregation according to the level of radioactivity of the facilities. Radiation safety is an important aspect in the design of nuclear research centers. The proposed Nuclear Research Center (by the author) in North Western Coast of Egypt proved to be the best among all the Egyptian nuclear centers in terms of design and planning, taking into account the radiation safety considerations. The Nuclear Research Center in Inshas was proved to be better than the Hot Laboratories and Waste Management Center in Inshas which proved to be better than the National Center for Radiation Research and Technology in Nasr City. 


\section{Recommendations}

It is recommended that the nuclear research centers should include some basic facilities and equipment that are necessary for developing the nuclear research activities and different applications in the nuclear field.

It is recommended to establish a new nuclear research center in a suitable site in north western coast of Egypt. This site is highly suitable and satisfies many of the site requirements. It is recommended to use the proposed design of a new nuclear research center. It is recommended to leave an area in the master plan for future expansion. It is recommended that the architects can design the different types of nuclear facilities. They should be able to work in close cooperation with other people from different departments. The task of the architects in the design of nuclear facilities is to create an efficient and functional facility for nuclear research and development.

The architects are recommended to design and plan the nuclear research centers taking into consideration the radial planning concept because it is the best with regard to radiation safety requirements.

\section{References}

[1] Munce, J. F. 1964. The Architect in the Nuclear Age. The Design of Buildings to House Radioactivity. London:
Iliffe Book Ltd.

[2] Egyptian Atomic Energy Authority. 2015. "EAEA Chairman's Statement." Egyptian Atomic Energy Authority. Accessed August 11, 2015. http://www.eaea.org.eg/Default_en.aspx.

[3] Google Earth. 2015. "Map of the Greater Cairo Governorates." Google Earth. Accessed April 26, 2015. http: //wikimapia.org/\#lang=en\&lat=30.286679\&lon=31. $393218 \& \mathrm{z}=16 \& \mathrm{~m}=\mathrm{b} \& \mathrm{search}=\% \mathrm{D} 8 \% \mathrm{~A} 7 \% \mathrm{D} 9 \% 86 \% \mathrm{D} 8 \%$ B4\%D8\%A7\%D8\%B5.

[4] Egyptian Atomic Energy Authority. 1998. Atomic Energy Authority. Cairo: EAEA.

[5] Egyptian Atomic Energy Authority. 1998. Egypt's Second Research Reactor (The Multi-Purpose Reactor). Cairo: EAEA.

[6] Egyptian Atomic Energy Authority. 2015. Egypt Second Research Reactor Complex. Cairo: EAEA.

[7] Egyptian Atomic Energy Authority. 2015. Radioisotopes Production Facility ETRR-2 Complex, Atomic Energy Authority, Egypt. Cairo: EAEA.

[8] The ABDAC (Arab Bureau for Design and Architectural Consultancies) at Abbasia. 2015. National Center for Radiation Research and Technology. Cairo: Egyptian Atomic Energy Authority.

[9] Pacer Consultants \& PUD (Planning \& Urban Development) Consultants. 1983. Master Plan of the North West Coastal Zone. Cairo: Pacer Consultants \& PUD Consultants.

[10] Egyptian Atomic Energy Authority. 2009. Regulatory Requirements for Site Approval Permit of Nuclear Power Plants in Egypt. Cairo: National Center for Nuclear Safety and Radiation Control.

[11] Ferguson, W. R. 1973. Practical Laboratory Planning. London: Applied Science Publishers Ltd. 